\title{
Use of telemedicine by practising allergists before and during the SARS-CoV-2 pandemic
}

\section{A survey among members of the Association of German Allergists (AeDA)}

\author{
Stephanie Dramburg · Paolo Maria Matricardi · Ingrid Casper · Ludger Klimek
}

Received: 18 January 2021 / Accepted: 3 March 2021 / Published online: 11 June 2021

(C) The Author(s) 2021

\begin{abstract}
Summary
Background The severe acute respiratory syndrome coronavirus type 2 (SARS-CoV-2) pandemic presented unprecedented challenges to both inpatient and outpatient care. In order to maintain good care under necessary contact restrictions, especially in the outpatient sector, the use of telemedical applications was demanded and promoted. The exploratory survey among members of the Association of German Allergists (AeDA) was intended to show how these were received among allergists in private practice.

Methods The survey was restricted to actively practising members of the AeDA who had previously given their consent to receive such surveys $(n=437)$. They were invited by email to participate in a survey on the topic of "Telemedicine in everyday clinical practice in allergology". The survey included quantitative and qualitative questions on the use of telemedicine services before and during the pandemic and was conducted anonymously on the SoSci Survey platform. Participation was possible in the period from June to August 2020.
\end{abstract}

\footnotetext{
Gender reference For reasons of easier readability, the masculine form of language is used in this article for personal nouns and pronouns. However, this does not imply any discrimination against the female or diverse gender, but is to be understood as gender-neutral in the sense of linguistic simplification.

S. Dramburg $(\bowtie) \cdot$ P. M. Matricardi

Department of Pediatric Respiratory Medicine, Immunology and Critical Care Medicine, Charité-Universitätsmedizin Berlin, Augustenburger Platz 1, 13353 Berlin, Germany stephanie.dramburg@charite.de

I. Casper · L. Klimek

Centre for Rhinology and Allergology Wiesbaden,

Wiesbaden, Germany
}

Results In all, 76 specialists with additional qualification in allergology took part in the survey. Of these, 71 completed the full questionnaire. Before the start of the pandemic-related contact restrictions, $46.5 \%(33 / 71)$ stated that they had used telemedicine in their clinical practice. This number increased to $73.2 \%(52 / 71)$ after 31 January 2020. The largest increase $(4.3 \%$ vs. $15.6 \%)$ was seen in the area of video consultations. Furthermore, 43/76 participants can imagine integrating telemedicine services into their daily clinical routine in the future.

Conclusion The use of telemedical services, especially video consultations, increased significantly during the SARS-CoV-2 pandemic in Germany. The majority of respondents perceive the implementation as positive and can imagine continuing to use telemedical methods after the end of the pandemic.

Keywords Telemedicine - Video consultation · COVID-19 · Allergology $\cdot$ Digitalisation

\section{Introduction}

The measures adopted by the federal government in spring 2020 to restrict the spread of severe acute respiratory syndrome coronavirus 2 (SARS-CoV-2) were widely implemented by the population, which initially led to a successful reduction in coronavirus disease 2019 (COVID-19) incidence. At the same time, however, a significant reduction in outpatient doctor-patient contacts became apparent, which posed new challenges for regular medical care in many respects. Regionally, a decrease in contacts of up to $75 \%$ could be observed with the same physician presence [1]. In order to continue to ensure continuous care for patients under contact restrictions and in times of concern about the risk of infection, the German Federal Ministry of Health called for and promoted the 
Table 1 Description of the survey participants

\begin{tabular}{|c|c|c|}
\hline & $n$ & $\%$ \\
\hline Total number of participants & 76 & 100 \\
\hline \multicolumn{3}{|l|}{ Gender } \\
\hline Female & 40 & 52.6 \\
\hline Male & 36 & 47.4 \\
\hline \multicolumn{3}{|l|}{ Age group (in years) } \\
\hline $31-40$ & 2 & 2.6 \\
\hline $41-50$ & 18 & 23.7 \\
\hline $51-60$ & 32 & 42.1 \\
\hline $61-70$ & 24 & 31.6 \\
\hline \multicolumn{3}{|l|}{ Specialisation $^{a}$} \\
\hline Allergology & 48 & 63.2 \\
\hline Otorhinolaringology & 32 & 42.1 \\
\hline Dermatology & 24 & 31.6 \\
\hline Pneumology & 9 & 11.8 \\
\hline Internal medicine ${ }^{b}$ & 2 & 2.6 \\
\hline Pediatrics & 5 & 6.6 \\
\hline General medicine & 4 & 5.3 \\
\hline Occupational Medicine & 1 & 1.3 \\
\hline Other & 7 & 9.2 \\
\hline
\end{tabular}

use of telemedical applications, especially video consultation. After the ban on exclusive remote treatment had already been relaxed in 2018 [2], the National Association of Statutory Health Insurance (SHI) Physicians now published simplified instructions for the implementation of telemedical services [3] including lists of certified technology providers [4] and corresponding remuneration structures [5]. While a survey by Stiftung Gesundheit described a clear increase in the use of telemedicine applications in 2020 [6], a survey of different participants in the health care system showed that the necessity, processes and benefits in different care structures differ significantly in some cases [7]. Although the authors also show a high acceptance of telemedical services across all professions, their implementation in different care scenarios seems to be confronted with different hurdles. For example, respondents from private clinics were more positive about the potential of telemedicine than their colleagues in private practices. In order to describe the implementation and use of different telemedicine methods in the everyday clinical practice of allergology specialists, we conducted an online survey among members of the Association of German Allergologists (AeDA).

\section{Methods}

Among AeDA members, those actively practising in the branch who had previously given consent to receive such surveys $(n=437)$ were invited by email and advertisement to voluntarily participate in the online survey on telemedicine service use behaviour between 17 June and 31 August 2020. The survey included questions on the age group, gender and specialty of the participants as well as on the use of telemedicine before and after the introduction of the pandemicrelated contact restrictions. There was also a survey on the use of different technologies and a questionnaire on the desire to continue offering telemedicine applications in the future. Possible complications of telemedical offers were also surveyed and participants were asked to indicate who took the decision regarding the justifiability of remote treatment. The date for differentiating the periods before and after the pandemic-related contact restrictions was set at 31 January 2020. The cross-sectional survey was conducted anonymously and in compliance with data protec-

Table 2 Use of telemedical applications and specification of the technologies used before and after 31 January 2020

\begin{tabular}{|c|c|c|c|c|c|}
\hline & \multicolumn{2}{|c|}{ Before 31 January 2020} & \multicolumn{3}{|c|}{ After 31 January 2020} \\
\hline & $n$ & $\%$ & $n$ & $\%$ & $p$-value \\
\hline Use of telemedicine applications ${ }^{a}$ & 33 & 46.5 & 52 & 73.2 & $<0.005$ \\
\hline Total $^{\mathbf{b}}$ & 117 & 100 & 192 & 100 & - \\
\hline Video consultation & 5 & 4.3 & 30 & 15.6 & $<0.005$ \\
\hline Telephone consultations (>10 min) & 24 & 20.5 & 39 & 20.3 & 0.01 \\
\hline Data transfer via digital platforms & 6 & 5.1 & 9 & 4.7 & 0.42 \\
\hline Data transfer via e-mail & 23 & 19.7 & 30 & 15.6 & 0.22 \\
\hline Digital doctor-patient communication & 5 & 4.3 & 9 & 4.7 & 0.26 \\
\hline Apps for healthcare professionals & 7 & 6.0 & 8 & 4.2 & 0.78 \\
\hline Therapy apps & 4 & 3.4 & 4 & 2.1 & 1.00 \\
\hline Symptom monitoring apps & 6 & 5.1 & 11 & 5.7 & 0.20 \\
\hline Exposure apps & 13 & 11.1 & 15 & 7.8 & 0.67 \\
\hline Digital exchange with colleagues & 11 & 9.4 & 18 & 9.4 & 0.15 \\
\hline Online appointment & 9 & 7.7 & 16 & 8.3 & 0.12 \\
\hline Other & 4 & 3.4 & 3 & 1.6 & 0.70 \\
\hline
\end{tabular}


Fig. 1 Perceived influence of telemedicine applications on everyday clinical life (The questions were completed by 76 and 73 participants respectively.)

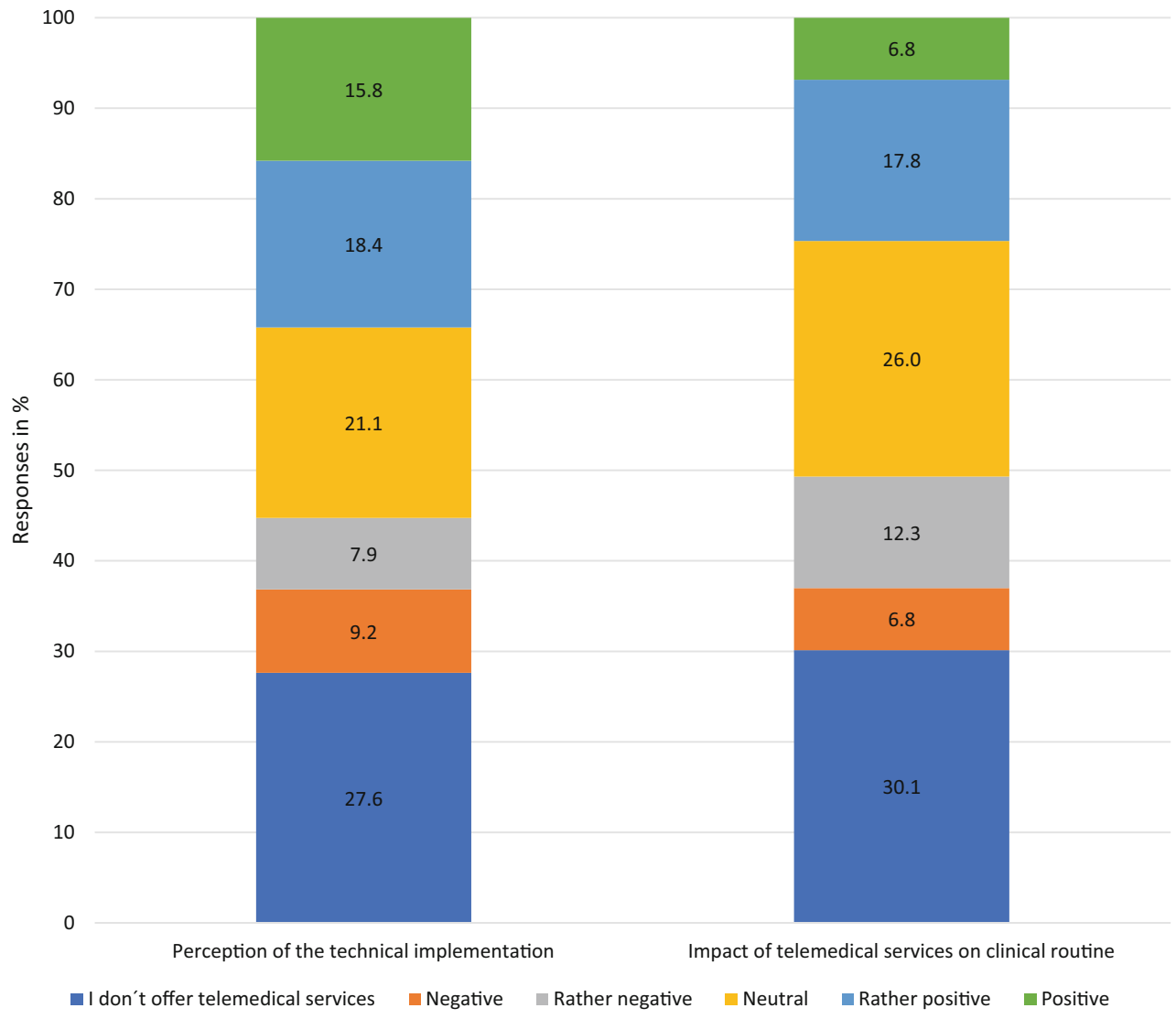

tion regulations using the web-based survey platform SoSci Survey [8]. The descriptive data analysis was carried out using Microsoft Excel, version 16.44.

\section{Results}

Seventy-six specialists (17.4\%) with an additional qualification in allergology took part in the survey; 71 questionnaires were completed in full. The participants were $52.6 \%$ female and $42.1 \%$ belonged to the age group 51-60 years (Table 1).

In addition to allergology ( $n=48 ; 63.2 \%)$, otorhinolarynoglogy $(n=32 ; 42.1 \%)$ and dermatology $(n=24$; $31.6 \%$ ) were among the most frequent specialities. With regard to the use of telemedicine applications, $46.5 \%(33 / 71)$ stated that they had already made use of them before 31 January 2020. This figure increased significantly to $73.2 \%(52 / 71)$ for use after 31 January 2020. The specification of technologies used showed stable trends in telephone consultations before and after the pandemic-related restrictions (20.5\%; $24 / 117$ vs. $20.3 \%$; $39 / 192$ respectively), while the largest increase was observed in the area of video consultations $(4.3 \%$; $5 / 117$ vs. $15.6 \%$; 30/192). The use of other technologies, such as patient-centred apps or digital exchange with colleagues, was stable at a low level, with no significant differences before and after the onset of the SARS-CoV-2 pandemic (Table 2).

The question about the perception of the technical implementation of telemedicine measures in their practice/clinic was answered by $55.3 \%$ of the respondents as "neutral", "rather positive" or "positive" (21.1\%; 18.4\%; 15.8\% respectively), while 50.6\% of the participants gave this assessment with regard to the influence of telemedicine offers on their daily clinical routine (26\% neutral; $17.8 \%$ rather positive; 6.8\% positive) (Fig. 1).

When asked who makes the decision on the justifiability of a (purely) telemedical consultation in individual cases, all participants answered that this decision is made within the clinic/practice itself. An external service provider was not entrusted with this decision among the respondents. In the majority of cases $(62 \%)$, the specialists themselves decide whether the use of telemedical applications is appropriate or not (Fig. 2). Complications in connection with telemedical consultation were described by 9 of the 52 (17.3\%) colleagues. Free-text statements on their quality revealed difficulties or delays in diagnostic decisionmaking as well as limitations in the clinical assessment of findings and communication problems with individual patients.

When looking to the future, $56.6 \%$ of the respondents stated that they could imagine using telemedicine services in their daily clinical routine even after the current pandemic situation, while $21.1 \%$ were not yet able to make this decision conclusively and $18.4 \%$ rejected its use (Fig. 3). When asked for free comments and wishes regarding teleallergology, respondents expressed a heterogeneous 
Fig. 2 Decision-makers on the justifiability of telemedical counselling in individual cases

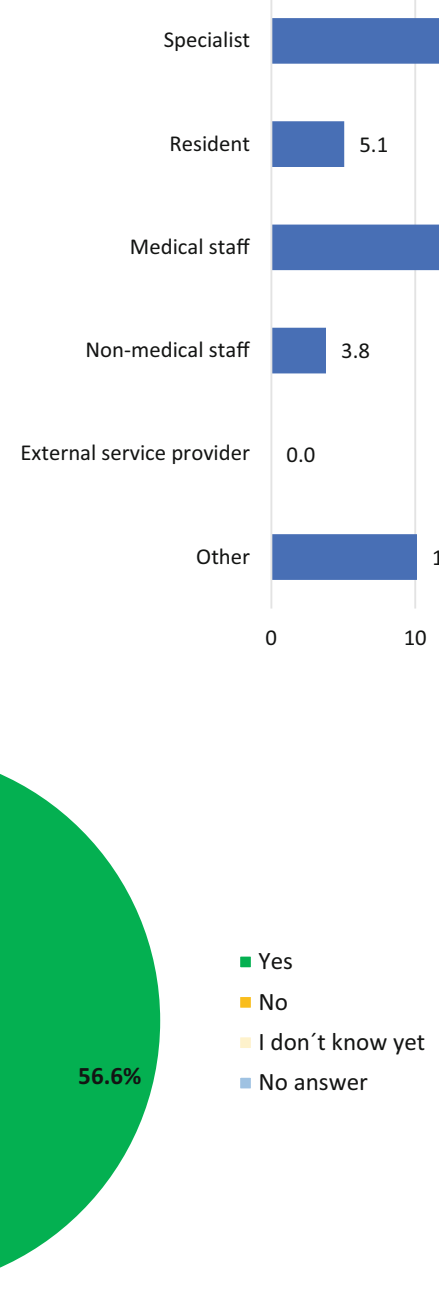

Fig. 3 Statements on the desire to continue using telemedicine applications in the future $(n=76$, figures in \%)

spectrum from enthusiastic support to strict rejection of telemedicine methods. However, participants repeatedly described a lack of time and personnel capacities for an additional telemedical offer or for dealing with its implementation.

\section{Discussion}

The survey of practising allergists on the use of telemedicine in their daily clinical routine in times of the COVID-19 pandemic showed a significant increase in the use of telemedical methods, especially with regard to video consultations.

The low response rate of $17.4 \%$ is most likely due to a certain fatigue regarding professional surveys around the COVID-19 pandemic and its impact on clinical practice. Although the majority of respondents were positive about the integration of telemedicine into everyday clinical practice, overall, a rather heterogeneous picture emerged in the freetext responses, which reflects the cross-section and corresponds to the data of Peine et al. collected in different care settings across professions [7].

It is also noteworthy that the decision on the justifiability of remote treatment is made in most cases by the specialists themselves and is not delegated to external service providers by any of the respondents. This should be evaluated in the light of the physician's duty of care and liability [9], although the offer or scheduling of video consultation hours for defined scenarios by trained practice staff is conceivable, especially for known patients.

While the technical implementation of telemedical services is perceived as "neutral" to "positive" by the majority of participants, there is greater heterogeneity with regard to the influence of the new methods on everyday clinical practice. In free-text comments, it was repeatedly noted that the time-management during busy daily practice routine can be perceived as a challenge or that a lack of time and personnel resources can be a hurdle. Although the associations of SHI-accredited physicians have made support offers available, additional offers from the professional associations and practice-oriented training courses can further facilitate the integration of new technologies into existing structures.

Overall, more than half of the participants were in favour of continuing to offer telemedical consultations in the future, which is to be welcomed, especially with regard to specialist care in structurally weak regions.

Funding Open Access funding enabled and organized by Projekt DEAL.

Conflict of interest S. Dramburg, P.M. Matricardi, I. Casper and L. Klimek declare that they have no competing interests.

Open Access This article is licensed under a Creative Commons Attribution 4.0 International License, which permits use, sharing, adaptation, distribution and reproduction in any medium or format, as long as you give appropriate credit to the original author(s) and the source, provide a link to the Creative Commons licence, and indicate if changes were 
made. The images or other third party material in this article are included in the article's Creative Commons licence, unless indicated otherwise in a credit line to the material. If material is not included in the article's Creative Commons licence and your intended use is not permitted by statutory regulation or exceeds the permitted use, you will need to obtain permission directly from the copyright holder. To view a copy of this licence, visit http://creativecommons.org/licenses/by/4.0/.

\section{References}

1. KVB with the support of the KVB Scientific Advisory Board. Position paper: End the medical shutdown-get the use of outpatient care in Bavaria back on track quickly! 2020. https://www.kvb.de/presse/statements/revitalisierungder-ambulanten-versorgung-in-bayern. Accessed 30 May 2021.

2. German Medical Association. Notes and explanations on § 7 Para. 4 MBO-Ä-Treatment in personal contact and remote treatment. Dtsch Arztebl. 2019;116:A-978 / B-810 / C-798.

3. KVB. Service for practices: video consultation. https:// www.kbv.de/html/videosprechstunde.php. Accessed 30 May 2021.
4. KVB. List of certified video service providers. https:/ / www. $\mathrm{kbv} . \mathrm{de} / \mathrm{media} / \mathrm{sp} /$ Liste_zertifizierte-Videodienstanbieter. pdf. Accessed 30 May 2021.

5. KVB. Videosprechstunde: Übersicht zur Vergütung. https://www.kbv.de/media/sp/Videosprechstunde_ uebersicht_Verguetung.pdf. Accessed 30 May 2021.

6. Stiftung Gesundheit, Health Innovation Hub. Physicians in the future market of health 2020: physician work and use of video consultation hours during the Covid 19 pandemic. 2020. https://www.stiftung-gesundheit.de/pdf/ studien/aerzte-im-zukunftsmarkt-gesundheit_2020.pdf;. Accessed 14 Dec 2020.

7. Peine A, Paffenholz P, Martin L, Dohmen S, Marx G, Loosen SH. Telemedicine in Germany during the COVID19 pandemic: multi-professional national survey. J Med Internet Res. 2020;22:e19745.

8. SoSci Survey GmbH. Online survey. https://www. soscisurvey.de. Accessed 30 May 2021.

9. Wolf T. Coordination office telemedicine Baden-Württemberg. Liability in case of breach of medical duty of care.. https:/ / www.telemedbw.de/FAQ-Haftung/haftungbei-verstoss-gegen-aerztliche-sorgfaltspflicht;. Accessed 14 Dec 2020. 